\title{
腾冲黑空山粗安岩中镁铁质-超镁铁质包体的 特征及成因初探
}

\author{
于红梅"，林传勇，史兰斌，许建东，陈孝德 \\ 中国地震局地质研究所, 北京 100029 \\ * E-mail: yuhongmei188@163.com \\ 收稿日期: 2009-08-30; 接受日期: 2010-06-02 \\ 地震行业科研专项(编号: 200708-27)资助
}

\begin{abstract}
摘要腾冲黑空山粗安岩中含有较多的镁铁质和超镁铁质微型包体, 主要为辉长岩类、辉 石岩类和极少量的二辉橄榄岩, 直径多小于 $2.5 \mathrm{~cm}$. 辉长岩类包体具有“开放”结构, 常有气 孔和基质的贯入, 辉石岩类包体以等粒结构和镶嵌结构为特征, 它们的矿物成分与熔岩斑 晶 (斜长石 + 单斜辉石 + 斜方辉石) 成分相近. 辉长岩类和辉石岩类包体平衡温度为 $1000 \sim 1125^{\circ} \mathrm{C}$, 与熔岩斑晶结晶温度 $\left(998 \sim 1108^{\circ} \mathrm{C}\right)$ 基本一致. 辉长岩和辉石岩类包体结构和 成分均有别于下地壳和幔源包体，应来源于岩浆房内部，其中辉长岩类包体是岩浆上升到 岩浆房顶部时结晶作用后形成的晶体-气泡-液体带, 而辉石岩类包体则岩浆房底部形成的 堆积体. 极少量的二辉橄榄岩包体具残斑结构, 组成矿物及成分类似于我国东部幔源包体 特征, 来源于上地幔, 由补给岩浆将其带入岩浆房中, 并且在岩浆喷发到地表之前可能经受 过冷却作用。包体的形成过程反映了岩浆的上升、停留、演化和喷发过程.
\end{abstract}

关键词

岩浆房

包体

斑晶

地质温压计

腾冲黑空山火山
由碱性玄武岩浆携带到地表的上地幔和下地壳 的岩石碎片通常被称为幔源和下地壳捕虏体或包体, 它们可以直接提供有关上地幔和下地壳的信息. 自 20 世纪 70 年代以来, 国内外在相关的岩石学、矿物 学、地球化学以及岩石圈动力学和流变学等领域 ${ }^{[1 ~ 4]}$ 开展了大量的研究工作. 另外, 有些辉长岩类和超镁 铁质包体并非来自下地壳或上地幔, 而是岩浆房内 堆积体的碎片 ${ }^{[5 \sim 7]}$, 对其研究可以提供有关岩浆房作 用过程的信息, 例如意大利Stromboli高钾钻碱性玄 武质熔岩中的镁铁质和超镁铁质包体与寄主熔岩存 在共岩浆作用(comagmatism), 反映了岩浆的上升和
储存过程 ${ }^{[8]}$.

腾冲黑空山火山岩含有较丰富的岩石包体 ${ }^{[9]}$, 但 未被详细研究, 目前尚不清楚它们是来自深部岩石 圈的岩石包体, 还是代表了岩浆房中形成的堆积体 碎片. 本文将详细研究黑空山火山岩中岩石包体的 结构、成分和平衡温度, 并与寄主熔岩中的斑晶进行 成分对比, 从而探讨它们的来源、成因以及岩浆活动 指示意义.

\section{1 地质概况及样品采集}

腾冲火山区位于三江地区高黎贡-怒江右旋走滑

引用格式: Yu H M, Lin C Y, Shi L B, et al. Characteristics and origin of mafic and ultramafic xenoliths in trachyandesite lavas from Heikongshan volcano, Tengchong, Yunnan Province, China. Sci China Earth Sci, 2010, 53: 1295-1306, doi: 10.1007/s11430-010-4044-6 
断裂带西侧的滕冲地块(图 1(a)), 在 $98^{\circ} 15^{\prime} \sim 98^{\circ} 45^{\prime} \mathrm{E}$ 和 $24^{\circ} 40^{\prime} \sim 25^{\circ} 30^{\prime} \mathrm{N}$ 、近南北方向 $90 \mathrm{~km} \times 50 \mathrm{~km}$ 的范围

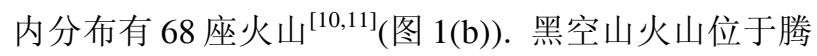
冲县城北约 $25 \mathrm{~km}$ 处 $\left(98^{\circ} 30^{\prime} \mathrm{E}, 25^{\circ} 13.8^{\prime} \mathrm{N}\right)$, 海拔高度 达 $2072 \mathrm{~m}$, 是区内火山机构保存最完整的火山之一. 火山锥体下部为熔岩雉, 上部为岩渣雉, 火口缘较完 整. 黑空山火山自中更新世以来多次间歇性溢出 ${ }^{[12]}$, 自雉体向西、北、东三个方向分布着大面积熔岩流,
至少可以分出四期 (图 1(c)), 最新喷发年代为

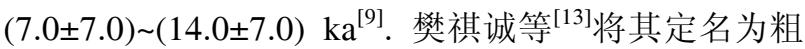
安岩, 并且认为它们属于高钾钙碱性火山岩系.

本次研究在黑空山火山第 II IV 期熔岩中共采集 火山岩样品 33 件, 采样位置标示于图 1(c). 所采集的 样品中有 22 件含有镁铁质和超镁铁质包体，包体个 体较小, 最大直径约为 $2.5 \mathrm{~cm}$, 大多数在 $1 \mathrm{~cm}$ 左右或 甚至更小.
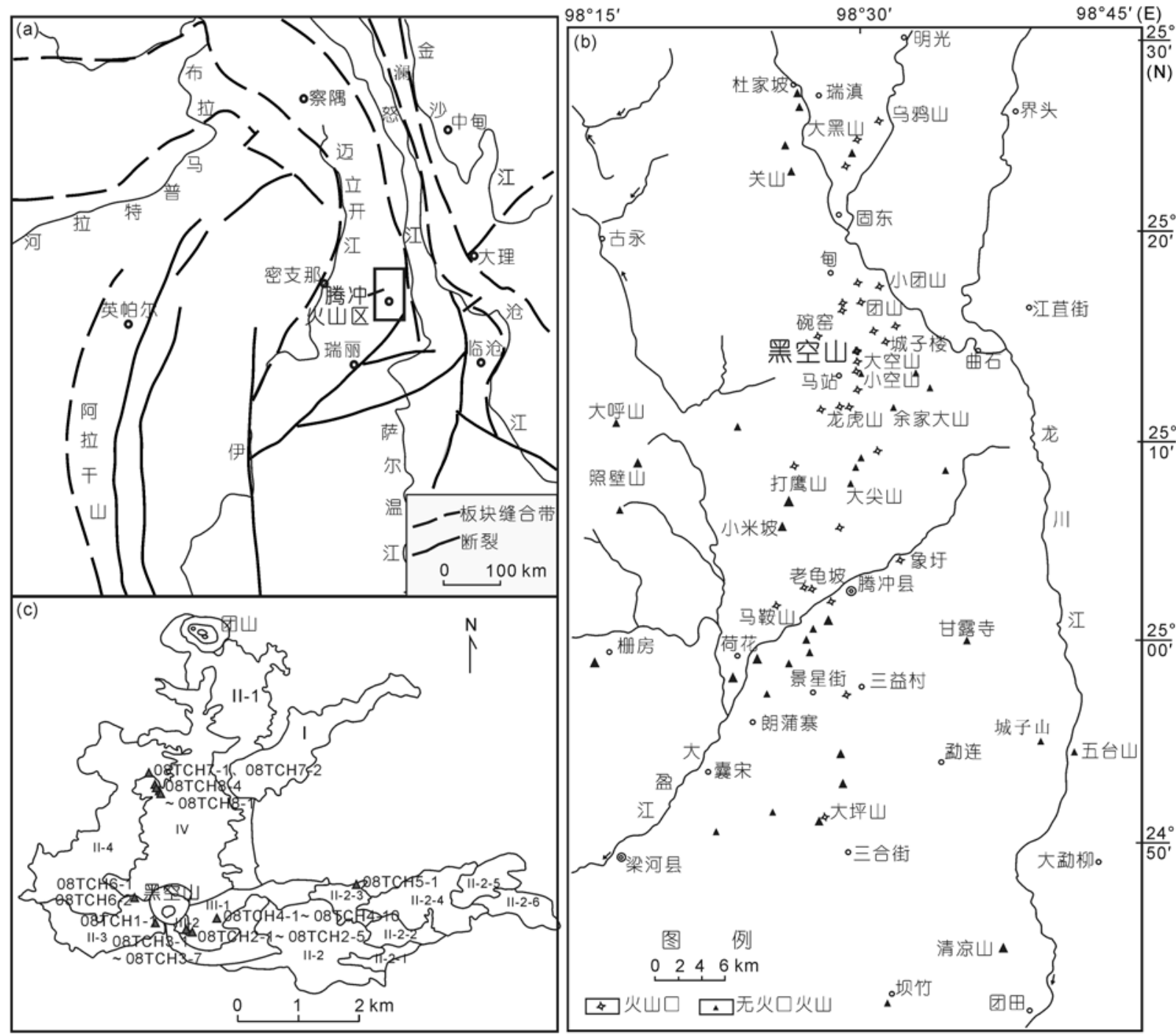

图 1 腾冲火山区区域构造及黑空山火山位置图

(a) 腾冲火山区区域构造示意图 ${ }^{[10]}$. (b) 腾冲火山区新生代火山分布图 ${ }^{[1]}$. (c) 腾冲黑空山火山流动单元划分及采样位置图(底图引自刘若新 等 ${ }^{11}$; 罗马数字为流动单元编号, 三角符号表示采样位置, 08TCH1-1 等为样品编号

1) 刘若新, 李荫葶, 樊祺诚, 等. 《三个火山区的喷发规模、物理及化学过程研究》项目报告. 2000 


\section{2 熔岩和包体的基本特征}

\section{1 熔岩的基本特征}

黑空山粗安岩宏观表现为渣状熔岩、结壳熔岩和 块状熔岩等. 气孔发育, 但大小、分布不均匀, 形态 多变, 有圆形、卵形和拉长形等. 熔岩呈斑状结构, 斑晶含量从 $2 \%$ 到 $8 \%$ 左右不等, 以斜长石和辉石为 主, 少量橄榄石. 斜长石斑晶大小不一 $(0.3 \sim 3 \mathrm{~mm})$, 但自形程度较高, 多呈长板状, 发育复合双晶(图 2(a)), 少量发育有环带(图 2(b)). 少量斜长石斑晶受 熔蚀作用而边缘圆化或呈港湾状, 内部有岩浆基质 的贯入(图 2(c)). 辉石斑晶 $(0.3 \sim 3.0 \mathrm{~mm}$ )多呈短柱状, 少量见有生长双晶发育, 沿裂纹或解理有岩浆基质 的贯入(图 2(d)). 斑晶中均未见如变形双晶、扭折带、 变形纹等明显的变形现象, 表明它们是岩浆结晶的 斑晶, 而非捕虏晶 ${ }^{[14,15]}$. 基质主要由隐晶质组成, 多 数样品中含有数量不等的玻璃质, 如图 2(a)中, 针状 微晶含量较少, 而图 2(b)和(d)中有大量的针状微晶.

\section{2 包体的基本特征}

黑空山熔岩中的包体虽属于微型包体, 但主要 作为一个整体与熔岩的界限分明, 少量具有反应边, 明显不同于联斑. 也有少量包体与联斑较难区分, 但 Laiolo 等 ${ }^{[8]}$ 将联斑等同于包体的碎片, 称之为晶体团 (crystal clots).

根据包体的矿物组成，可以分为镁铁质和超镁 铁质两大类, 前者主要为辉长岩类, 后者主要为辉石 岩类, 此外有 1 件为二辉橄榄岩. 辉长岩类包体据其 矿物成分和含量可以进一步划分为辉长岩、辉长苏长 岩、苏长岩和橄榄苏长岩, 但本文未进行细分, 而是 统称为辉长岩类包体. 同样, 辉石岩类包体除了将含 有橄榄石的特别注明以外，也未进一步细分(见表 1).

二辉橄榄岩包体, 主要由橄榄石、单斜辉石和少 量斜方辉石组成. 在包体的内部有细小的橄榄石和 辉石重结晶颗粒(见图 3(a)中部)，构成残斑结构，表 明它们经历了一定程度的塑性变形.

辉石岩类包体主要由单斜辉石和斜方辉石组成,
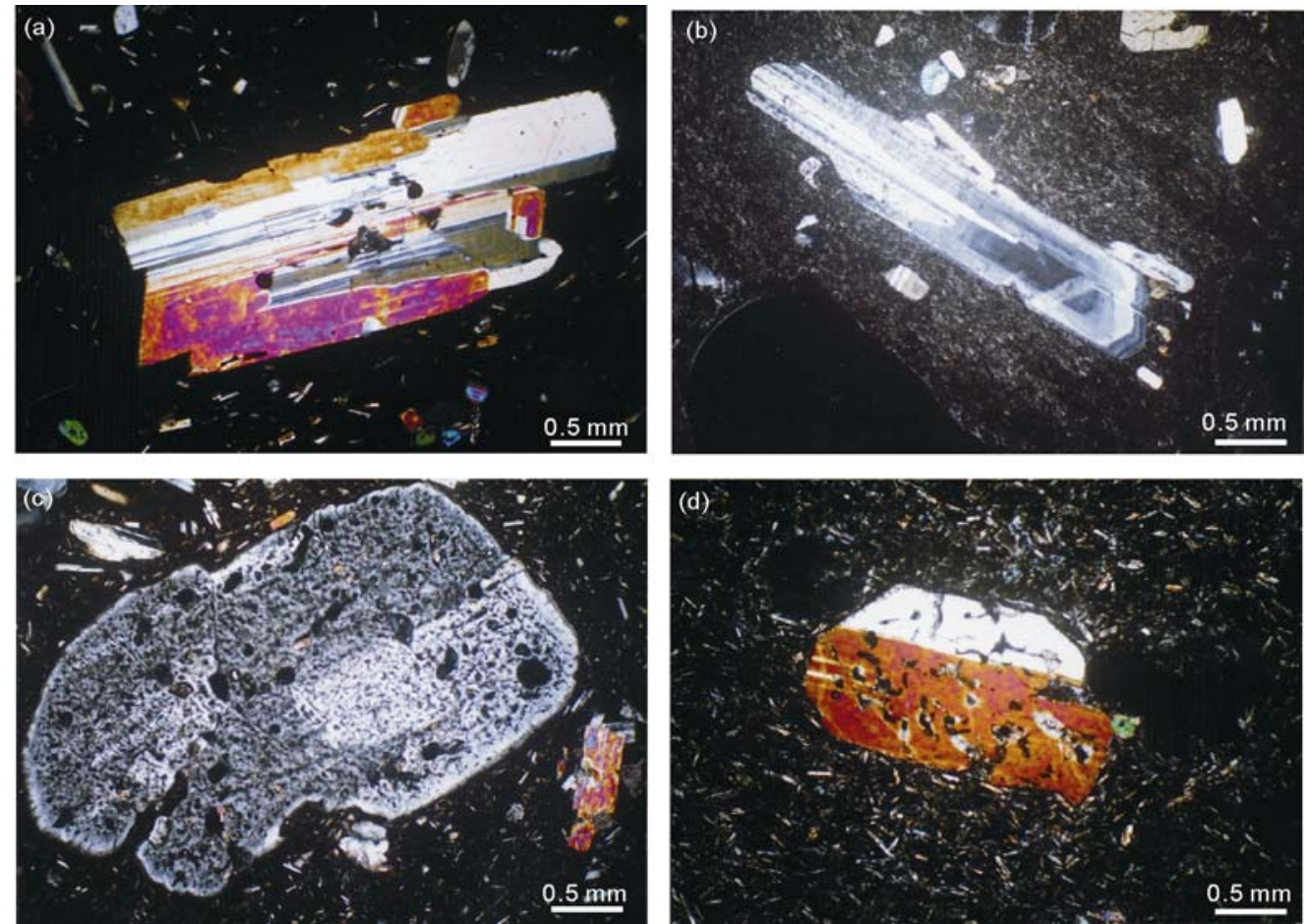

图 2 黑空山熔岩的显微结构特征

均为正交偏光. (a) 08TCH2-5 样品, 板状斜长石斑晶, 复合双晶发育; (b) 08TCH3-5 样品, 板状斜长石斑晶, 右下角可见环带构造; (c) 08TCH2-5 样品, 斜长石斑晶, 边缘圆化或呈港湾状, 内部有基质的贯入; (d) 08TCH7-4 样品, 短柱状辉石斑晶, 生长双晶发育, 沿裂 缝和解理有岩浆基质贯入 
其中 08TCH4-3-3 含有 10\%以下的橄榄石, 为橄榄辉 石岩(见表 1). 少数辉石岩类包体仅由单斜辉石组成, 例如 08TCH4-7-1, 单斜辉石呈短柱状和粒状, 颗粒 边界多呈曲线状. 包体内部没有明显的孔隙和熔岩
基质的贯入，呈近等粒镶嵌结构(图 3(b)). 在这些包 体中均未发现明显的变形现象.

辉长岩类包体主要由斜长石、单斜辉石和斜方辉 石组成, 少量含有橄榄石(如 08TCH3-5-1 含 $0.2 \%$ 橄

表 1 黑空山火山镁铁质、超镁铁质包体的基本特征 ${ }^{\text {a) }}$

\begin{tabular}{|c|c|c|c|c|c|c|c|c|c|}
\hline 包体号 & 岩性 & $\mathrm{Pl}(\%)$ & $\mathrm{Cpx}(\%)$ & $\mathrm{Opx}(\%)$ & $\mathrm{Ol}(\%)$ & $\mathrm{Gl}(\%)$ & $\mathrm{V}(\%)$ & 粒度(mm) & 结构 \\
\hline 08TCH2-1-1 & 辉长岩 & 45.9 & I & 54.1 & I & 8.5 & 1.1 & $0.1 \sim 0.6$ & 辉长结构 (开放) \\
\hline 08TCH2-1-2 & 辉长岩 & 60.2 & 27.6 & 11.2 & I & 11.2 & 10.0 & $0.2 \sim 0.6$ & 辉长结构 (开放) \\
\hline 08TCH2-2-1 & 二辉橄榄岩 & I & 40.2 & 12.6 & 47.2 & I & I & $0.3 \sim 1.5$ & 残斑结构 \\
\hline 08TCH2-4-1 & 辉长岩 & 34.8 & 49.3 & 9.4 & I & 6.5 & I & $0.5 \sim 1.7$ & 辉长结构(开放) \\
\hline 08TCH3-1-1 & 辉石岩 & I & 64.4 & 35.6 & I & I & I & $1.0 \sim 1.6$ & 近等粒结构 \\
\hline 08TCH3-1-2 & 辉长岩 & 52.7 & 47.3 & l & l & l & I & $0.5 \sim 1.2$ & 辉长-辉绿结构 \\
\hline 08TCH3-5-1 & 橄榄辉长岩 & 64.8 & I & 35.0 & 0.2 & I & 2.0 & $0.5 \sim 1.7$ & 辉绿结构(开放) \\
\hline 08TCH3-5-3 & 橄榄辉长岩 & 25.1 & I & 59.4 & 15.5 & I & I & $0.1 \sim 1.0$ & 辉长-辉绿结构 \\
\hline 08ТCH3-7-1 & 辉长岩 & 51.4 & 48.6 & I & I & l & I & $0.5 \sim 1.5$ & 辉长-辉绿结构 \\
\hline 08TCH4-3-1 & 辉长岩 & 53.4 & 46.6 & I & I & I & I & $0.3 \sim 0.6$ & 辉长-辉绿结构 \\
\hline 08TCH4-3-3 & 橄榄辉石岩 & I & 65.2 & 25.4 & 9.4 & l & I & $0.1 \sim 0.6$ & 近等粒结构 \\
\hline 08TCH4-5-1 & 辉长岩 & 51.4 & 48.1 & l & l & l & I & $0.5 \sim 1.5$ & 辉长-辉绿结构 \\
\hline 08TCH4-7-1 & 辉石岩 & l & 100 & I & I & I & I & $0.1 \sim 0.5$ & 近等粒镶嵌结构 \\
\hline 08TCH8-1-1 & 辉石岩 & I & 75.3 & 24.7 & I & I & I & $0.2 \sim 0.5$ & 近等粒结构 \\
\hline 08TCH8-3-1 & 辉长岩 & 47.8 & I & 52.2 & l & 9.2 & 11.5 & $0.3 \sim 1.0$ & 辉长结构 (开放) \\
\hline
\end{tabular}

a) 矿物百分含量统计数据为体积百分比, 统计方法为线截距法, 不包括基质和气孔; Pl 为斜长石, $\mathrm{Cpx}$ 为单斜辉石, $\mathrm{Opx}$ 为斜方辉石, $\mathrm{Ol}$ 为橄榄石, $\mathrm{Gl}$ 为玻璃基质, $\mathrm{V}$ 为气孔
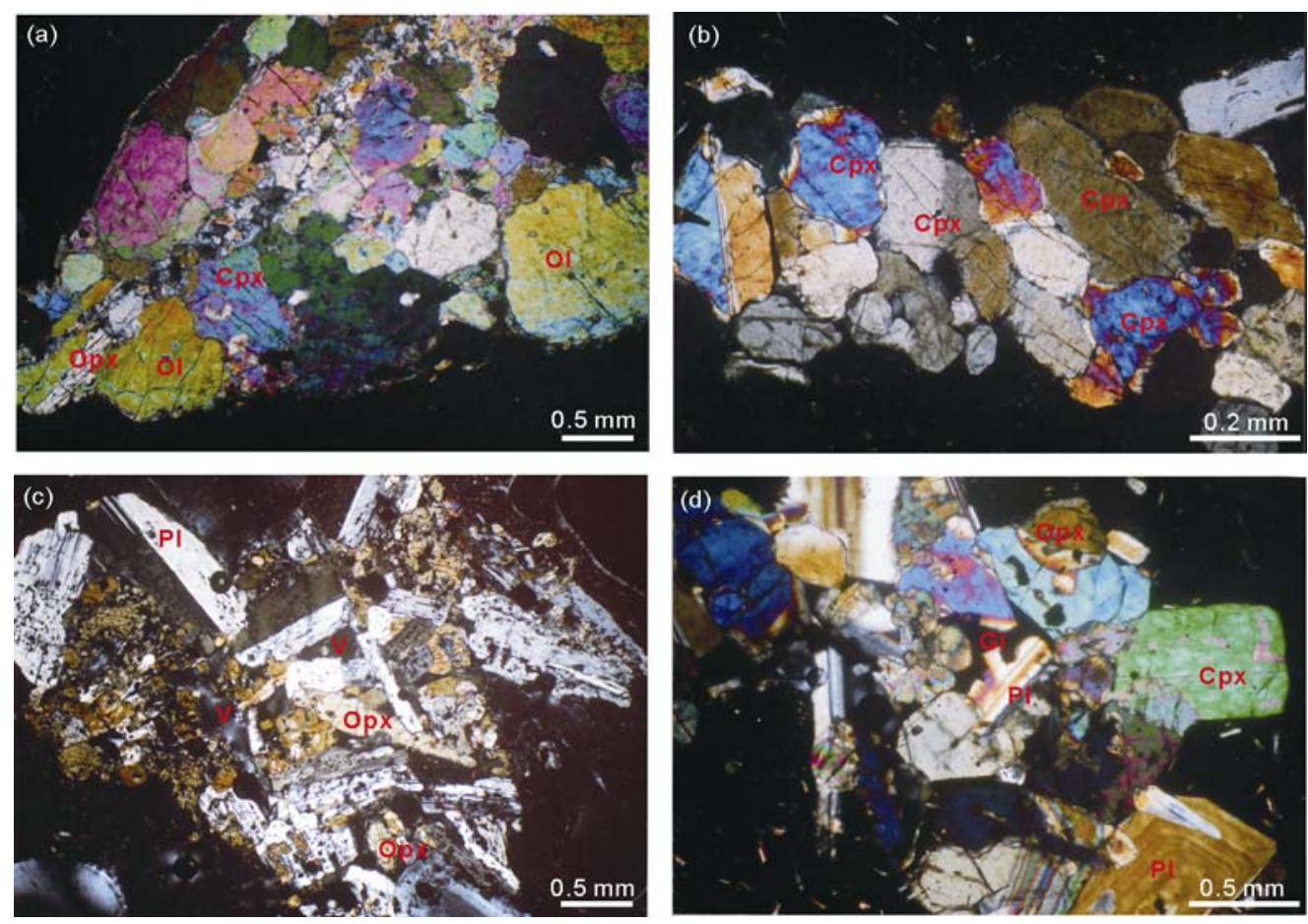

图 3 包体的显微结构特征

均为正交偏光. (a) 08TCH2-2-1 包体, 二辉橄榄岩包体, 残斑结构; (b) 08TCH4-7-1 包体, 辉石岩类包体, 近等粒镶嵌结构; (c) 08TCH3-5-1 包 体, 辉长岩类包体, 辉绿结构; (d) $08 \mathrm{TCH} 2-2 \mathrm{~b}-2$ 包体, 辉长岩类包体, 辉长结构 
榄石, 08TCH3-5-3 含 15.5\%橄榄石). 斜长石多呈板状, 自形程度较高, 其间充填有短柱状和粒状的辉石晶 粒, 构成辉绿结构(图 3(c)); 部分包体中斜长石和辉 石近等粒, 均为半自形, 构成辉长结构 (图 3(d)). 在 这些辉长岩类包体中, 矿物没有明显的变形现象, 多 有气孔和熔岩基质的贯入(见图 3(c), (d)), 可称之为 “开放”结构(“open” texture) $)^{[5 \sim 7]}$.

\section{3 寄主熔岩斑晶、包体和基质的化学成分}

本文对包体的组成矿物及寄主熔岩中部分斑晶 和基质进行了电子探针成分分析. 大部分分析在中 国科学院地质与地球物理研究所电子探针实验室完 成, 仪器为 CAMECA SX-51 型电子探针仪, 工作条 件为加速电压 $15 \mathrm{kV}$, 电子束流 $20 \mathrm{nA}$, 束斑直径 1 2 $\mu \mathrm{m}$ (测定长石时束斑直径 7 8 $\mu \mathrm{m}$ ). 小部分分析在中 国地质大学 (北京) 电子探针实验室完成, 仪器为 SHIMADZU EPMA-1600, 工作条件为加速电压 15 $\mathrm{kV}$, 电子束流 $8 \mathrm{nA}$, 束斑直径 $2 \mu \mathrm{m}$. 为了确定矿物 成分是否具有成分分带性或不均一性, 多数采用多 点测定.

\section{1 寄主熔岩斑晶和包体矿物的化学成分对比}

(1) 斜长石. 寄主熔岩中的斜长石斑晶成分变化 范围较宽 $\left(\mathrm{Or}_{1.95 ~ 5.66} \mathrm{Ab}_{30.84 \sim 68.22} \mathrm{An}_{26.86 \sim 67.21}\right)$, 属拉长 石、中长石或更长石(表 2 和图 4). 另外还含有两个 碱性长石, 成分分别为 $\mathrm{Or}_{58.58} \mathrm{Ab}_{35.43} \mathrm{An}_{5.99}$ 和 $\mathrm{Or}_{27.45} \mathrm{Ab}_{71.88} \mathrm{An}_{0.66}$. 辉长岩类包体中的斜长石, 其成 分大部分集中在 $\mathrm{Or}_{1.70 \sim 4.13} \mathrm{Ab}_{33.12 \sim 46.07} \mathrm{An}_{51.06 \sim 64.38}$ 之间, 属拉长石; 另有 1 个包体样品的斜长石 $\mathrm{An}$ 高达 77.77(图 4). 辉长岩类包体的斜长石成分范围明显比 寄主熔岩中斜长石斑晶的成分范围小得多, 其重叠 的部分主要集中在An 51 65.

(2) 单斜辉石. 单斜辉石斑晶端员组成变化为 $\mathrm{Wo}_{36.65 \sim 43.94} \mathrm{En}_{43.7 \sim 51.84} \mathrm{Fs}_{8.88 \sim 14.14}$, 其 $\mathrm{CaO}, \mathrm{Al}_{2} \mathrm{O}_{3}$ 和 $\mathrm{TiO}_{2}$ 含量分别为 $16.93 \mathrm{wt} \% \sim 20.52 \mathrm{wt} \%, 3.07 \mathrm{wt} \% \sim 5.75 \mathrm{wt} \%$ 和 $0.42 \mathrm{wt} \% \sim 1.04 \mathrm{wt} \%, \mathrm{Mg}^{\#}$ 为 $75.4 \% \sim 82.5 \%$. 辉长岩 类包体中的单斜辉石端员组成变化主要为 $\mathrm{Wo}_{39.12 \sim 44.07} \mathrm{En}_{44.53 \sim 48.85} \mathrm{Fs}_{9.95 \sim 14.11}$, 其 $\mathrm{CaO}, \mathrm{Al}_{2} \mathrm{O}_{3}$ 和 $\mathrm{TiO}_{2}$ 含量分别为 $18.63 \mathrm{wt} \%$ 20.62 $\mathrm{wt} \%, 2.84 \mathrm{wt} \% \sim 4.97 \mathrm{wt} \%$ 和 $0.40 \mathrm{wt} \% \sim 1.12 \mathrm{wt} \%, \mathrm{Mg}^{\#}$ 为 $76.5 \% \sim 80.8 \%$. 其中, 只 有一个包体 (08 TCH3-7-1) 例外, 可能受蚀变

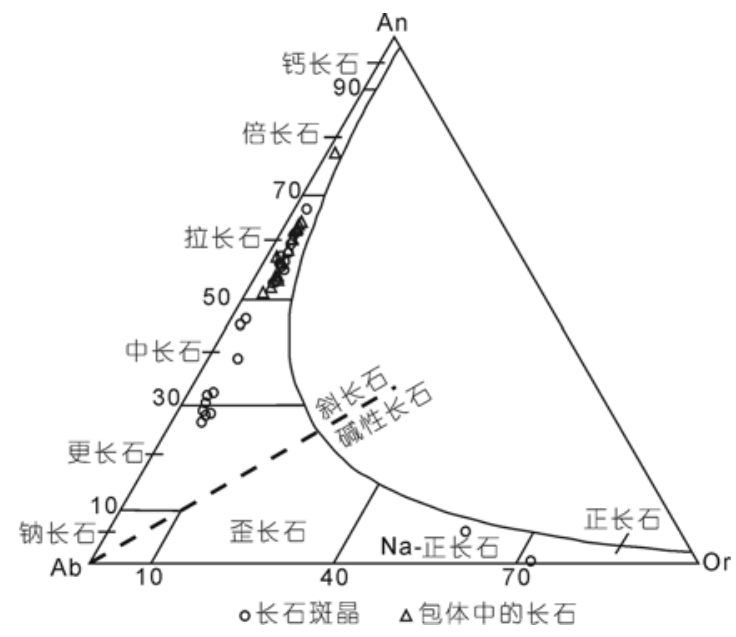

图 4 熔岩和包体中长石成分 Ab-Or-An 图 $\mathrm{Ab}$-钠长石, Or-正长石, An-钙长石. 据Smith ${ }^{[16]}$

作用, 其 $F s$ 高达 17.61, 而 $\mathrm{Mg}^{\#}$ 只有 $68.7 \%$ (图 5). 辉石 岩类包体的单斜辉石端员组成变化为 $\mathrm{Wo}_{38.00 \sim 43.45} \mathrm{En}_{45.37 \sim 51.3} \mathrm{Fs}_{8.50 \sim 13.11}$, 其 $\mathrm{CaO}, \mathrm{Al}_{2} \mathrm{O}_{3}$ 和 $\mathrm{TiO}_{2}$ 含量分别为 $17.89 \mathrm{wt} \% \sim 20.82 \mathrm{wt} \%, 1.29 \mathrm{wt} \%$ $5.01 \mathrm{wt} \%$ 和 $0.22 \mathrm{wt} \% \sim 0.98 \mathrm{wt} \%, \mathrm{Mg}^{\#}$ 为 $77.5 \% \sim 84.0 \%$. 总体上, 单斜辉石斑晶、辉长岩类包体中的单斜辉石 和辉石岩类包体中的单斜辉石成分变化相似, 大部 分属于普通辉石, 少量为顽透辉石. 但是, 二辉橄榄 岩包体 (08TCH2-2-1) 的单斜辉石成分明显不同, $\mathrm{Mg}^{\#}$ 为 $94.6 \%$ 95.4\%, 端员组成为 $\mathrm{Wo}_{45.61 ~ 50.33} \mathrm{En}_{48.20 \sim 51.14}$

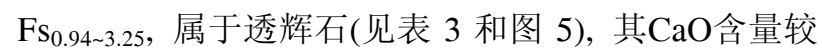
高 $\left(22.79 \mathrm{wt} \%\right.$ 25.6wt \%), $\mathrm{TiO}_{2}(0.02 \mathrm{wt} \%)$ 和 $\mathrm{Al}_{2} \mathrm{O}_{3}$ (0.45wt\% 0.86wt\%) 含量则明显低于其他单斜辉石.

(3) 斜方辉石. 斜方辉石斑晶端员组成变化为 $\mathrm{Wo}_{2.69 \sim 3.53} \mathrm{En}_{73.43 \sim 80.25} \mathrm{Fs}_{16.14 \sim 23.99}$, 其 $\mathrm{TiO}_{2}$ 含量为 $0.22 \mathrm{wt} \% \sim 0.48 \mathrm{wt} \%, \mathrm{Mg}^{\#}$ 为 $75.2 \% \sim 82.5 \%$. 辉长岩类包

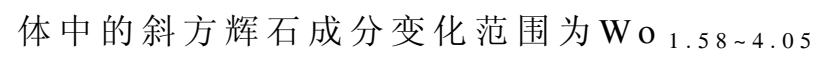
$\mathrm{En}_{71.49 \sim 80.35} \mathrm{Fs}_{16.53 \sim 25.79}$, 其 $\mathrm{TiO}_{2}$ 含量为 $0.06 \mathrm{wt} \%$ $0.63 \mathrm{wt} \%, \mathrm{Mg}^{\#}$ 为 $73.7 \%$ 83.3\% (表 3 和图 5). 辉石岩类 包体中的斜方辉石端员组成变化为 $\mathrm{Wo}_{2.89 \sim 5.20} \mathrm{En}$ 75.97 79.96 $\mathrm{Fs}_{16.63 \sim 20.48}$, 其 $\mathrm{TiO}_{2}$ 含量为 $0.17 \mathrm{wt} \% \sim 0.54 \mathrm{wt} \%$, $\mathrm{Mg}^{\#}$ 为 $79.4 \% \sim 82.2 \%$. 总体上, 斜方辉石斑晶、辉长 岩类包体中的斜方辉石和辉石岩类包体中的斜方辉 石成分大部分重合, 均为古铜辉石. 其中, 含有橄榄 石的辉石岩包体 (08 T C H 4-3-3) 和辉长岩包体 (08TCH3-5-1 和 08TCH3-5-3), 其斜方辉石成分与其 他辉石岩包体中的斜方辉石成分并无差别. 但是, 唯 
表 2 腾冲黑空山火山岩中斑晶矿物的电子探针分析结果 ${ }^{a)}$

\begin{tabular}{|c|c|c|c|c|c|c|c|c|c|c|c|c|c|c|c|c|c|}
\hline & 物 & $\mathrm{O}_{2}$ & $\mathrm{TiO}_{2}$ & $\mathrm{Al}_{2} \mathrm{O}_{3}$ & $\mathrm{Cr}_{2} \mathrm{O}_{3}$ & $\mathrm{MgO}$ & $\mathrm{CaO}$ & $\mathrm{MnO}$ & $\mathrm{FeO}$ & $\mathrm{NiO}$ & $\mathrm{Na}_{2} \mathrm{O}$ & $\mathrm{K}_{2} \mathrm{O}$ & 总计 & $\mathrm{Mg}^{\#}$ & $\mathrm{Wo} / \mathrm{Ab}$ & En/Or & Fs/An \\
\hline \multirow[t]{4}{*}{ 08TCH2-1 } & $\mathrm{Pl}$ & 3.69 & 0.09 & 29.36 & 0.05 & 0.07 & 11.91 & 0.03 & 0.50 & n.d. & 4.67 & 0.53 & 100.89 & & 40.24 & 3.02 & 56.74 \\
\hline & Pl & 03 & 10 & .08 & 0.04 & 0.10 & 71 & & 44 & 0.01 & 52 & 57 & 99.71 & & & 29 & 6.41 \\
\hline & Pl 核 & .96 & 16 & 3.04 & n.d. & n.d. & 10.72 & 0.04 & 0.44 & n.d. & 33 & 61 & 98.80 & & & 60 & 3.10 \\
\hline & Pl 边 & 54.26 & 0.01 & 28.79 & n.d. & n.d. & 11.41 & & 0.21 & n.d. & 35 & 0.49 & 99.47 & & & 94 & .44 \\
\hline \multirow[t]{8}{*}{ 08TCH2-2 } & Cpx & 51.17 & 0.67 & 3.37 & 0.24 & 16.18 & 20.52 & 0.14 & 6.84 & n.d. & 45 & 0.01 & 99.58 & 80.8 & & .65 & .88 \\
\hline & $\mathrm{Cpx}$ & 52.89 & 0.60 & 3.07 & 0.20 & 16.33 & 18.96 & 0.26 & 7.71 & n.d. & 0.37 & n.d. & 100.38 & 79.1 & .59 & 47.42 & 2.99 \\
\hline & Cpx & 52.92 & 0.73 & 4.07 & 0.42 & 16.33 & 18.44 & 0.01 & 7.66 & n.d. & & 0.13 & 101.21 & & & 18 & 2.70 \\
\hline & Opx & 55.50 & 0.25 & 1.62 & 0.08 & 27.95 & 1.41 & 0.46 & 13.50 & n.d. & 24 & n.d. & 101.01 & & & 6.02 & 1.22 \\
\hline & Opx & 53.89 & 0.48 & 2.80 & 0.12 & 26.67 & 1.36 & 0.30 & 15.15 & n.d. & d. & n.d. & 100.76 & 15. & 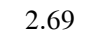 & 3.43 & 3.88 \\
\hline & Opx & 53.86 & 0.35 & 2.43 & 0.06 & 27.97 & 1.79 & & 12.92 & n.d. & & n.d. & 99.74 & & & & .61 \\
\hline & Pl & 52.21 & 0.06 & 30.32 & 0.06 & 0.09 & 12.95 & 0.03 & 0.40 & 0.06 & 07 & 0.42 & 100.65 & & & 39 & 2.25 \\
\hline & $\mathrm{Pl}$ & 56.33 & 0.16 & 27.05 & n.d. & n.d. & 9.48 & 0.03 & 0.49 & n.d. & 81 & 0.45 & 99.80 & & & 61 & 6.18 \\
\hline \multirow[t]{6}{*}{ 08TCH3-1 } & Pl 核 & 59.50 & 0.19 & 24.62 & n.d. & 0.15 & 6.79 & 0.10 & 0.28 & n.d. & & 0.52 & 99.78 & & & 92 & 1.98 \\
\hline & $\mathrm{Pl}$ 边 & 60.76 & 0.06 & 23.87 & n.d. & n.d. & 5.88 & 0.20 & 0.10 & n.d. & 55 & 0.85 & 99.37 & & & 88 & 8.36 \\
\hline & Pl & 60.28 & 0.07 & 25.44 & 0.02 & n.d. & 6.89 & 0.01 & 0.19 & 0.02 & 44 & 0.73 & 101.07 & & & 08 & 2.46 \\
\hline & Cpx & 51.90 & 0.69 & 3.70 & 0.13 & 16.62 & 19.70 & 0.22 & 6.79 & n.d. & 46 & n.d. & 100.20 & 8 & & 8.55 & 10.09 \\
\hline & Pl & 61.07 & 0.03 & 24.64 & 0.05 & 0.02 & 5.76 & n.d. & 0.19 & n.d. & 99 & 0.89 & 100.73 & & & & 6.86 \\
\hline & Q & 99.18 & 0.05 & n.d. & 0.04 & n.d. & n.d. & n.d. & n.d. & 0.01 & & 0.01 & 99.29 & & & & \\
\hline \multirow[t]{4}{*}{ 08ТCH3-5 } & Opx & 54.14 & 0.23 & 2.10 & 0.18 & 28.44 & 1.66 & 0.24 & 12.05 & 0.07 & 0.04 & n.d. & 99.14 & 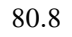 & 7 & 78.17 & 18.55 \\
\hline & 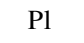 & 53.43 & 0.04 & 29.45 & 0.02 & 0.14 & 2.28 & n.d. & 0.37 & n.d. & 8 & 0.53 & 100.64 & & & & 8.93 \\
\hline & Cpx & 52.05 & 0.42 & 4.81 & 0.17 & 17.22 & 16.93 & 0.31 & 6.50 & n.d. & 4 & 0.03 & 98.78 & 82.5 & 65 & 84 & 11.51 \\
\hline & Cpx & 51.02 & 0.87 & 5.7 & 0.34 & 15.45 & 20.36 & 0.16 & 6.01 & 0.02 & & n.d. & 100.53 & & & 38 & 69 \\
\hline $08 \mathrm{TC}$ & 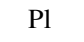 & 51.92 & 0.06 & 30.51 & 0.01 & 0.07 & 12.92 & n.d. & 0.44 & 0.01 & 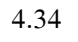 & 0.48 & 100.77 & & & & 0.53 \\
\hline \multirow[t]{5}{*}{ 08TCH4-7 } & Cpx & 50.92 & 0.79 & 3.46 & 0.18 & 15.42 & 20.23 & 0.27 & 7.77 & 0.06 & 8 & 0.03 & 99.50 & 78.0 & 00 & 8 & 11.42 \\
\hline & Opx & 53.52 & 0.33 & 2.29 & 0.09 & 26.31 & & 0.43 & 15.46 & 0.08 & & 0.02 & 100.07 & & & 99 & 3.99 \\
\hline & $\mathrm{Pl}$ & 53.61 & 0.10 & 29.60 & 0.11 & 0.06 & 12.14 & n.d. & 0.35 & n.d. & & 0.42 & 100.92 & & & 8 & 3.25 \\
\hline & $\mathrm{Pl}$ & 50.95 & 0.01 & 31.55 & 0.04 & 0.07 & 14.19 & d. & 0.39 & n.d. & & 0.35 & 101.14 & & & 5 & 67.21 \\
\hline & & & 0.22 & & 0.04 & 29.84 & & & 11.30 & 0.10 & & & 100.51 & & & 24 & 6.14 \\
\hline \multirow[t]{3}{*}{ 08ТCH8-1 } & 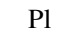 & 1 & 0.10 & 30.05 & $\mathrm{n}$ & 0.08 & 12.08 & 0.05 & 0.42 & 0.01 & 58 & 0.59 & 101.28 & & & & 57.36 \\
\hline & Opx & 5 & 35 & 3.05 & 0.08 & 28.74 & 145 & 0.23 & 12.28 & 0.06 & & 0.01 & 100.23 & 80. & & & 18.29 \\
\hline & Cpx & 50.29 & 1.04 & 5.37 & 0.06 & 15.28 & 20.38 & 0.30 & 7.33 & 0.05 & & 0.01 & 100.63 & & & & 0.08 \\
\hline \multirow[t]{4}{*}{ 08TCH8-3 } & $\mathrm{Pl}$ & 56.97 & 0.02 & 27.72 & 0.03 & 0.02 & 9.67 & n.d. & 0.17 & n.d. & 0 & 0.37 & 101.17 & & 0 & 8 & 45.33 \\
\hline & $\mathrm{Pl}$ & 60.76 & n.d. & 25.08 & 0.02 & n.d. & 6.45 & 0.02 & 0.20 & n.d. & & 0.67 & 100.87 & & & 76 & 30.47 \\
\hline & $\mathrm{P}$ & & n.d. & 26 & & t. & & & & & & 0.73 & & & & & 3.93 \\
\hline & Cpx & 51.96 & 0.64 & 4 & 0.10 & 16.38 & 19.62 & 0.18 & 6.49 & 0.01 & & n.d. & 99.72 & 81.8 & & 00 & 10.67 \\
\hline \multirow[t]{3}{*}{ 08TCH2-2ba } & $\mathrm{Pl}$ & 52.68 & 0.06 & 30.55 & 0.01 & 0.05 & 12.83 & 0.06 & 0.43 & 0.02 & 3.97 & 0.42 & 101.08 & & 35.03 & 43 & 62.54 \\
\hline & Opx & & 0.38 & & & & 1.5 & & & 0.06 & & n.d. & 100.46 & & & & 9.22 \\
\hline & Opx & 54.37 & 0.27 & 3.20 & 0.11 & 29.10 & 1.70 & 0.25 & 11.60 & 0.02 & & n.d. & 100.68 & 81.7 & & 44 & 17.22 \\
\hline \multirow[t]{3}{*}{ 08ТCH3-7 } & $\mathrm{Pl}$ & 59.11 & 0.01 & 26.01 & 0.04 & 0.03 & 8.20 & n.d. & 0.30 & 0.06 & 6.58 & 0.85 & 101.18 & & & 1 & 38.84 \\
\hline & $\mathrm{P}$ & & 0.05 & & $0 .($ & 0.0 & 10.99 & & 0. & 0.05 & & 0.67 & 100.72 & & & & 53.30 \\
\hline & $\mathrm{Pl}$ & 66. & 0.02 & 18.98 & & n.d & 0.1 & n.d. & 0.09 & 0.02 & & 12.23 & 101.20 & & & & 0.66 \\
\hline \multirow[t]{6}{*}{ 08TCH2-4 } & $\mathrm{Pl}$ & & 0.01 & 29.48 & 0.03 & 0.10 & 12.12 & 0.01 & 0.38 & 0.01 & & 0.73 & 101.13 & & 40.30 & 98 & 55.72 \\
\hline & $\mathrm{Q}$ & & & & & & & & & & & & & & & & \\
\hline & & & & & & & & & & & & & & & & & \\
\hline & $\mathrm{Cp}$ & & 0.7 & & 0.2 & 16.3 & 19. & 0. & & 0.0 & & & 99 & & & & .08 \\
\hline & $\mathrm{Pl}$ & & & & & & & & & $\mathrm{n}$. & & & & & & & 28.50 \\
\hline & Pl & & & & 0. & & & & 1.9 & & & 6.6 & & & & & 5.99 \\
\hline \multirow[t]{4}{*}{ 08TCH4-5 } & $\mathrm{Cpx}$ & & & & 0. & & 19.83 & 0.21 & & 0.03 & & n.d & & 75 & 42.16 & 43.70 & 14.14 \\
\hline & & & & & & & & & & 0. & & & & & & & \\
\hline & $\mathrm{O}_{\mathrm{l}}$ & & & & & 20.99 & & & & 0.06 & & & & 81.3 & & & 17.28 \\
\hline & $\mathrm{Pl}$ & 53.90 & 0.09 & 29.32 & 0.10 & 0.12 & 11.78 & 0.03 & 0.49 & n.d. & 4.63 & 0.49 & 100.95 & & 40.40 & 2.81 & 56.79 \\
\hline
\end{tabular}

a) 矿物名称: Ol-橄榄石, Opx-斜方辉石, $\mathrm{Cpx}$-单斜辉石, Pl-斜长石, Q-石英. $\mathrm{Mg}^{\#}=100 \times \mathrm{Mg} /(\mathrm{Mg}+\Sigma \mathrm{Fe})$, n.d.表示低于检测限. $\mathrm{Ol}$ *镶嵌在 Opx斑晶中 
表 3 腾冲黑空山火山岩中包体矿物的电子探针分析结果 ${ }^{a)}$

\begin{tabular}{|c|c|c|c|c|c|c|c|c|c|c|c|c|c|c|c|c|c|}
\hline & 物 & & $\mathrm{O}_{2}$ & ${ }_{2} \mathrm{O}_{3}$ & ${ }_{2} \mathrm{O}_{3}$ & & $\mathrm{OO}$ & O & $\mathrm{O}$ & $\mathrm{O}$ & & ${ }_{2} \mathrm{O}$ & 41 & $\mathrm{Mg}^{\#}$ & & & \\
\hline \multirow[t]{2}{*}{ 08TCH2-1-1 } & Dpx & & 38 & & 16 & 33 & 17 & 28 & .08 & & & - & 9.67 & & 2.33 & 5.84 & 1.83 \\
\hline & $\mathrm{Pl}$ & & & & & & & & & & & & 1.00 & & & 36 & 7.77 \\
\hline \multirow[t]{3}{*}{ 08TCH2-1-2 } & Cpx & 66 & 65 & & 31 & 45 & & & & & & & .64 & 8.1 & 74 & 90 & 3.36 \\
\hline & $\mathrm{px}$ & & 24 & & & 54 & & & .63 & & & & & 5.2 & & 3.41 & 4.27 \\
\hline & 1 & .54 & .08 & .05 & 12 & 10 & 1.33 & & 46 & d. & & .61 & 01.19 & & 46 & 46 & 4.08 \\
\hline \multirow[t]{2}{*}{ 08TCH3-1-2 } & Cpx & .55 & .69 & 84 & .13 & 16.36 & 0.36 & 16 & 7.23 & 04 & & n.d. & 59 & 80.1 & 2.53 & 7.51 & .96 \\
\hline & D1 & & 10 & 69 & 04 & 0.13 & 3.31 & 01 & 0.40 & 0.01 & & 0.43 & 01.05 & & 3.12 & 2.50 & 4.38 \\
\hline \multirow[t]{3}{*}{ 08TCH3-5-1 } & $\mathrm{Ol}$ & .04 & 06 & 10 & 06 & 40.46 & .12 & 16 & 0.06 & $n d$ & & n.d. & 0.06 & 78.2 & & & \\
\hline & Opx & & 57 & 4.39 & & 5.27 & & & 5.56 & 01 & & .d. & & 74.3 & 32 & 55 & 0.15 \\
\hline & Pl & & 12 & 2979 & & & 2.07 & & 24 & .01 & & 30 & 1.02 & & 40.31 & 1.70 & 7.99 \\
\hline \multirow[t]{3}{*}{$08 \mathrm{TC}$} & $\mathrm{Ol}$ & & 10 & & & & & & .95 & & & 01 & & 6.9 & & & \\
\hline & Opx & & 35 & & & & & & & & & & & 78.7 & & & \\
\hline & $\mathrm{Pl}$ & & & & & & & & & & & & & & & 16 & \\
\hline \multirow[t]{2}{*}{ 08TCH4-3-1 } & Cpx & & & & & & & & & & & & & & & 6.67 & 1.93 \\
\hline & $\mathrm{Pl}$ & & 8 & 0.15 & & & & & & & & & & & & 2.30 & 5.44 \\
\hline \multirow[t]{3}{*}{ 08TCH4-3-2 } & Cpx & 28 & 84 & & 1 & 5.25 & 0 & & 04 & & & & 43 & 80.5 & 79 & 7.29 & 1.92 \\
\hline & Opx & & 39 & & & 6 & & & 4.92 & & & & & & & 3.39 & 2.79 \\
\hline & $r$ & 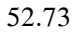 & .05 & .11 & 0.0. & 0.09 & 0.77 & & 0.37 & & & 而. & 100.78 & & 7.85 & 2.86 & .29 \\
\hline \multirow[t]{3}{*}{ 08TCH8-1-3 } & Cpx & 62 & 0.48 & 86 & & 16.34 & .44 & 07 & 7.33 & d. & & .0 & 65 & 79.9 & 9.28 & 8.41 & 2.31 \\
\hline & Opx & & 41 & 2.4 & 0.20 & 10 & & 4 & 2.16 & 03 & & u. & & 0.6 & & 8.17 & 3.96 \\
\hline & Pl & & 05 & 6 & & & 7 & 0 & & & & 57 & & & & .20 & 6.69 \\
\hline \multirow[t]{2}{*}{ 08TCH8-3-1 } & $\mathrm{O}_{\mathrm{r}}$ & & 20 & & & & & & 11 & & & & & 80.7 & & .14 & \\
\hline & $D$ & & 010 & & & & & & & & & & & & & 78 & 25 \\
\hline \multirow[t]{3}{*}{ 08TCH8-3-2 } & Cpx & & & & & & & & & & & & & 9.3 & & & \\
\hline & & & & & & & & & & & & & & 80.7 & & & \\
\hline & $\mathrm{Pl}$ & & & & & & & & & & & & & & & & \\
\hline \multirow[t]{3}{*}{ 08ТCH8-3-3 } & Сpx & & & & & & & & & & & & & .0 & & & 47 \\
\hline & & & & & & & & & & & & & & 1. & & & 71 \\
\hline & $\mathrm{P}$ & & & ). & & & & & & & & & & & & 42 & 3.04 \\
\hline 08TCH2-2b-2 & Cpx & & 0 & & & & ). & $2+2$ & & & & & & 79.3 & 66 & 02 & 0.32 \\
\hline & $\mathrm{Op}$ & & & & & & & & & & & & & 3.3 & & 34 & .53 \\
\hline & $\mathrm{P}$ & & 0.07 & 30. & & & & & & & & & & 32.6 & & 39 & 2.88 \\
\hline 08 & Cpx & & & & & & & & & & & & & 68.7 & & 25 & 7.61 \\
\hline & $\mathrm{P}$ & & & & & & & & & & & & & & & & \\
\hline 08 & & & & & & & & & & & & & & 18.5 & & 6.20 & 2.21 \\
\hline & $\mathrm{Pl}$ & & & & & & & & & & & & & & & & 1.22 \\
\hline 08TC & Cpx & & & & & & & & & & & & & 0.4 & & & .35 \\
\hline & & & & & & & & & & & & & & & & & 93 \\
\hline & $\mathrm{Pl}$ & & & & & & & & & & & & & & & 3 & 50 \\
\hline 08 & Cpx & & & & & & & & & & & & & 80.4 & & & 33 \\
\hline & & & & & & & & & & & & & & & & & \\
\hline 08TC & & & & & & & & & & & & & & & & & \\
\hline & & & & & & & & & & & & & & & & & 2 \\
\hline & & & & & & & & & & & & & & & & 49 & .33 \\
\hline & $\mathrm{O}$ & & & & & & & & & & & & & (1) & & 9.29 & 7.3. \\
\hline $08 \mathrm{TCl}$ & $\mathrm{O}$ & & & & & & & & & & & & & 70 & & & \\
\hline & & & & & & & & & & & & & & 79.7 & & & \\
\hline & & & & & & & & & & & & & & & & & \\
\hline $08 \mathrm{TC}$ & Cpx & & & & & & & & & & & & & 0.2 & & 46.95 & 1.44 \\
\hline 08TCH8-1 & Cpx & & & & & & & & & & & & & 3.5 & & 6.39 & 2.99 \\
\hline & $\mathrm{O}$ & & & & & & & & & & & & & .1 & & 76.09 & 9.13 \\
\hline & Cpx & & & & & & & & & & & & & .7 & & 3.24 & 9.01 \\
\hline 08T & Сpx & & & & & & 20. & & & & & & & 79.9 & 2.40 & 46.34 & 1.2 \\
\hline $2-1$ & $\mathrm{O}^{2}$ & & & & & & & & & & & & & & & & \\
\hline & $\mathrm{C}_{1}$ & & & & & & & & & & & & & & & & \\
\hline & $\mathrm{O}_{1}$ & & & & & & & & & & & & & 91 & & 89.45 & 3.83 \\
\hline 人) & Opx & 53.60 & (5) & .20 & 0.11 & 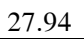 & 1.50 & 0.07 & 12.05 & n.d. & 0.07 & n.d. & 100.30 & 00.5 & 3.00 & 77.61 & $1, .07$ \\
\hline
\end{tabular}

a) 每个包体中矿物的成分数据大部分为 2 个以上测点的平均值 


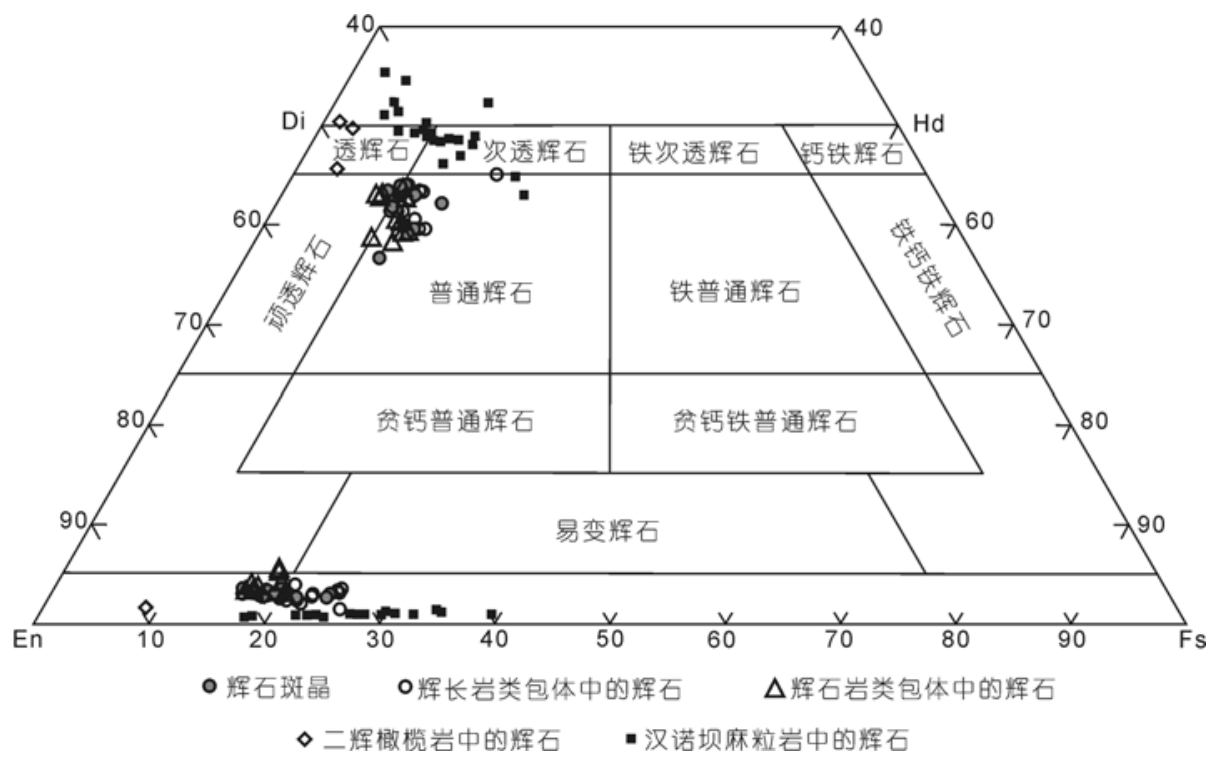

图 5 熔岩和包体中辉石分类图

汉诺坝麻粒岩中的辉石成分来自陈孝德等 ${ }^{[17]}$. Di-透辉石, Hd-䥻铁辉石, En- 顽火辉石, Fs-铁辉石 (据Poldervaart和Hess ${ }^{[18]}$ )

一的二辉橄榄岩包体(08TCH2-2-1)的斜方辉石成分 明显不同, 其端员组成为 $\mathrm{Wo}_{1.72} \mathrm{En}_{89.45} \mathrm{Fs}_{8.83}$, 属于顽 火辉石，其 $\mathrm{TiO}_{2}$ 含量仅 $0.03 \mathrm{wt} \%, \mathrm{Mg}^{\#}$ 为 $91.3 \%$. 而该 包体边缘的斜方辉石反应边的成分与辉长岩包体、辉 石岩包体和辉石斑晶中的斜方辉石成分相近.

(4) 橄榄石. 含橄榄石的辉长岩 $(08 \mathrm{TCH} 3-5-1$ 和 08TCH3-5-3)和辉石岩 $(08 \mathrm{TCH} 4-3-3)$ 包体中的橄榄石 Fo 为 $76.9 \%$ 78.2\%; 而二辉橄榄岩包体(08TCH2-2-1) 中的橄榄石Fo为 $90.6 \%$ 91.5\%, 为幔源包体的橄榄 石特征 ${ }^{[2]}$.

\section{2 玻璃基质的成分}

熔岩中玻璃基质(表 4)成分变化范围较大, $\mathrm{SiO}_{2}$ 为 $52.7 \mathrm{wt} \% \sim 68.6 \mathrm{wt} \%, \mathrm{Al}_{2} \mathrm{O}_{3}$ 为 $13.8 \mathrm{wt} \% \sim 29.8 \mathrm{wt} \%$, $\mathrm{K}_{2} \mathrm{O} / \mathrm{Na}_{2} \mathrm{O}$ 为 0.11 2.33. 在TAS图解中 (图 6)落在玄武 安山岩、玄武质粗安岩、粗安岩和粗面岩的区域, 反 映了连续的岩浆演化过程. 但是在同一流动单元的 不同样品中, 基质成分有所不同, 甚至在同一样品中, 基质成分也有所变化(例如 08TCH8-3 样品). 樊祺诚 等 ${ }^{[13]}$ 曾对黑空山熔岩做过全岩成分分析(见表 5), 其 中第 I 期落于粗面玄武岩区, 第 II IV 期均落于粗安 岩区. 这些成分反映原始的岩浆可能为玄武质岩浆, 但在第 I 期喷发时, 已演化成为粗面玄武质岩浆. 另 外, 贯入辉长岩包体中的基质, 其成分与熔岩中的偏
酸性基质类似.

\section{4 包体平衡温度、压力的计算}

镜下观察表明只有少数斜长石具有环带, 其他 矿物均无环带和变形现象; 此外, 采用同一温度计对 同一颗粒不同部位或同一包体不同颗粒测定结果进 行的计算差异很小 $\left(<30^{\circ} \mathrm{C}\right)$. 因此, 本文认为矿物达 到或是近似达到平衡, 可采用地质温度计计算其平 衡温度. 为了排除分析的偶然性, 根据前人的工作经 验 ${ }^{[5 \sim 8,13]}$, 计算时采用矿物成分的平均值. 在计算该 类包体的平衡温度时, 前人多采用Wells ${ }^{[20]}$, Wood和 $\mathrm{Bano}^{[21]}$, Brey和Kohler ${ }^{[22]}$ 的二辉石温度计 ${ }^{[5 \sim 8,14]}$. 因此, 本文也采用上述温度计. 但对于不含斜方辉石的样 品, 只能采用单斜辉石温度计来计算. 另外, Nimis单 斜辉石温度计 ${ }^{[23]}$ 所获结果偏差相对较小 ${ }^{[24]}$, 本文也 采用了该温度计进行计算(表 6). 除了个别情况外, 以上 4 种温度计计算结果较为一致, 辉石岩和辉长岩 包体的平衡温度在 $1000 \sim 1125^{\circ} \mathrm{C}$ 之间, 但唯一的二辉 橄榄岩包体却得到较低的平衡温度 $\left(825^{\circ} \mathrm{C}\right)$ (表 6 ).

由于辉石斑晶与岩浆处于平衡状态, 因此也采 用同样的温度计来计算斑晶的温度 ${ }^{[14]}$ (表 7). 结果表 明斑晶结晶温度在 $998 \sim 1108^{\circ} \mathrm{C}$ 之间，与包体的平衡 温度基本一致(二辉橄榄岩包体除外)。这表明，黑空 


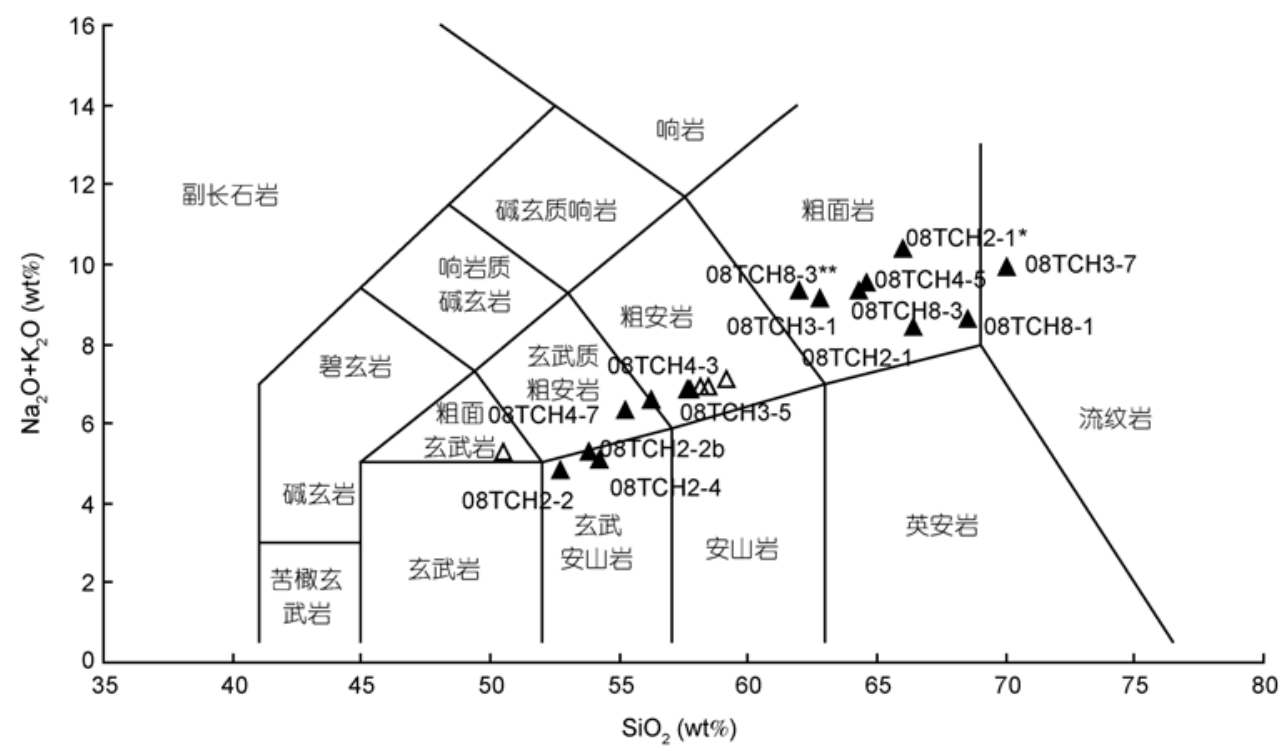

图 6 玻璃基质成分与全岩成分的 TAS 图解

实心三角符号表示玻璃基质成分; 空心三角符号表示全岩成分; 据Le Maitre等 ${ }^{[19]}$

表 4 火山玻璃主要成分a)

\begin{tabular}{cccccccccccccc}
\hline 流动单元 & 样品号 & $\mathrm{SiO}_{2}$ & $\mathrm{Cr}_{2} \mathrm{O}_{3}$ & $\mathrm{~K}_{2} \mathrm{O}$ & $\mathrm{Na}_{2} \mathrm{O}$ & $\mathrm{MgO}$ & $\mathrm{MnO}$ & $\mathrm{TiO}_{2}$ & $\mathrm{Al}_{2} \mathrm{O}_{3}$ & $\mathrm{FeO}$ & $\mathrm{CaO}$ & $\mathrm{NiO}$ & 总计 \\
\hline III-1 & 08TCH2-1 & 65.98 & 0.07 & 6.90 & 3.46 & 0.18 & 0.02 & 1.08 & 16.91 & 1.78 & 1.94 & 0.02 & 98.34 \\
& 08TCH2-1 & 66.44 & 0.04 & 5.23 & 3.18 & 0.19 & 0.03 & 1.27 & 15.73 & 2.19 & 2.32 & 0.02 & 96.64 \\
& 08TCH2-2b & 53.85 & 0.09 & 0.56 & 4.70 & 0.07 & n.d. & 0.13 & 28.89 & 0.58 & 11.52 & n.d. & 100.38 \\
& 08TCH2-2 & 52.74 & 0.04 & 0.49 & 4.36 & 0.09 & n.d. & 0.07 & 29.82 & 0.53 & 12.55 & n.d. & 100.67 \\
& 08TCH2-4 & 54.18 & 0.03 & 0.53 & 4.55 & 0.06 & n.d. & 0.09 & 28.60 & 0.59 & 11.56 & n.d. & 100.19 \\
III-2 & 08TCH3-1 & 62.78 & 0.09 & 2.96 & 6.17 & 0.03 & n.d. & 0.21 & 22.47 & 0.66 & 5.17 & n.d. & 100.54 \\
& 08TCH3-5 & 56.23 & n.d. & 1.28 & 5.31 & 0.17 & 0.04 & 0.15 & 27.15 & 0.86 & 9.62 & 0.01 & 100.81 \\
& 08TCH3-7 & 70.04 & 0.06 & 6.67 & 3.23 & 0.42 & 0.04 & 0.88 & 14.25 & 3.25 & 1.05 & n.d. & 99.88 \\
III-1 & 08TCH4-3 & 57.62 & 0.06 & 1.76 & 5.11 & 0.24 & n.d. & 0.45 & 25.17 & 1.54 & 8.63 & n.d. & 100.57 \\
& 08TCH4-5 & 64.60 & 0.06 & 5.95 & 3.56 & 0.86 & 0.19 & 2.17 & 13.82 & 6.59 & 2.12 & 0.05 & 99.97 \\
& 08TCH4-7 & 55.19 & 0.22 & 1.43 & 4.88 & 0.22 & 0.03 & 0.29 & 26.29 & 1.29 & 9.25 & 0.01 & 99.11 \\
IV & 08TCH8-1 & 68.56 & 0.03 & 6.03 & 2.59 & 0.33 & 0.03 & 1.67 & 14.37 & 3.16 & 0.92 & n.d. & 97.70 \\
& 08TCH8-3** & 64.28 & 0.01 & 6.00 & 3.36 & 1.25 & 0.08 & 1.27 & 15.24 & 4.85 & 2.71 & 0.02 & 99.07 \\
& 08TCH8-3** & 61.98 & n.d. & 5.32 & 4.05 & 1.73 & 0.12 & 1.66 & 15.18 & 5.96 & 3.72 & 0.01 & 99.74 \\
\hline
\end{tabular}

a) *08TCH2-1-1 包体中的基质, ** 两种颜色的基质

表 5 熔岩全岩成分 ${ }^{a)}$

\begin{tabular}{ccccccccccccc}
\hline 流动单元 & $\mathrm{SiO}_{2}$ & $\mathrm{~K}_{2} \mathrm{O}$ & $\mathrm{Na}_{2} \mathrm{O}$ & $\mathrm{MgO}$ & $\mathrm{MnO}$ & $\mathrm{TiO}_{2}$ & $\mathrm{Al}_{2} \mathrm{O}_{3}$ & $\mathrm{FeO}$ & $\mathrm{Fe}_{2} \mathrm{O}_{3}$ & $\mathrm{CaO}$ & $\mathrm{P}_{2} \mathrm{O}_{5}$ & 总计 \\
\hline $\mathrm{I}$ & 50.47 & 2.19 & 3.08 & 5.76 & 0.14 & 1.41 & 17.75 & 6.21 & 2.68 & 6.69 & 0.36 & 100.21 \\
II & 58.16 & 3.37 & 3.58 & 3.85 & 0.12 & 1.10 & 16.47 & 4.78 & 1.44 & 5.65 & 0.43 & 99.48 \\
III & 59.20 & 3.62 & 3.52 & 3.39 & 0.10 & 1.03 & 16.08 & 3.97 & 2.03 & 5.05 & 0.39 & 99.52 \\
IV & 58.43 & 3.43 & 3.48 & 3.73 & 0.11 & 1.10 & 16.36 & 4.56 & 1.73 & 5.56 & 0.42 & 99.47 \\
\hline
\end{tabular}

a) 据焚祺诚等 ${ }^{[13]}$ 
表 6 包体平衡温度计算结果 ${ }^{\text {a) }}$

\begin{tabular}{|c|c|c|c|c|c|}
\hline 包体编号 & 岩性 & $T(\mathrm{~W})$ & $T(\mathrm{WB})$ & $T(\mathrm{BK})$ & $T(\mathrm{~N})$ \\
\hline 08TCH2-1-2 & 辉长岩 & 1061 & 1035 & 1032 & 1092 \\
\hline 08ТСН3-1-2 & 辉长岩 & I & I & I & 1042 \\
\hline 08TCH4-3-1 & 辉长岩 & I & l & I & 1073 \\
\hline 08TCH4-3-2 & 辉长岩 & 1089 & 1057 & 1040 & 1096 \\
\hline 08TCH8-1-3 & 辉长岩 & 1125 & 1113 & 1110 & 1141 \\
\hline 08TCH8-3-2 & 辉长岩 & 1089 & 1087 & 1085 & 1100 \\
\hline 08TCH8-3-3 & 辉长岩 & 1000 & 1002 & 980 & 1006 \\
\hline 08TCH2-2b-2 & 辉长岩 & 1004 & 1042 & 1032 & 1009 \\
\hline 08TCH2-4-1 & 辉长岩 & 1037 & 1044 & 1027 & 1049 \\
\hline 08TCH4-5-1 & 辉长岩 & I & I & I & 1080 \\
\hline 08TCH3-1-1 & 辉石岩 & 1103 & 1104 & 1106 & 1114 \\
\hline 08ТCH3-5-2 & 辉石岩 & 1114 & 1113 & 1098 & 1120 \\
\hline 08TCH4-3-3 & 橄榄辉石岩 & 1113 & 1102 & 1102 & 1127 \\
\hline 08TCH4-7-1 & 辉石岩 & / & / & 1 & 1062 \\
\hline 08TCH8-1-1 & 辉石岩 & 1112 & 1101 & 1105 & 1126 \\
\hline 08TCH8-1-2 & 辉石岩 & I & I & I & 1055 \\
\hline 08TCH2-2b-1 & 辉石岩 & l & l & I & 1053 \\
\hline 08TCH2-2-1 & 二辉橄榄岩 & 825 & 948 & 742 & 739 \\
\hline
\end{tabular}

a) 单位: ${ }^{\circ} \mathrm{C}$. 地质温度计: $T(\mathrm{~W})$, Wells ${ }^{[20]}$ 二辉石温度计; $T(\mathrm{WB})$, Wood和Bano ${ }^{[2]]}$ 二辉石温度计; $T(\mathrm{BK})$, Brey和Kohler ${ }^{[22] 二}$ 辉石温度计; $T(\mathrm{~N}), \mathrm{Nimis}^{[23]}$ 单斜辉石温度计. 下同

表 7 斑晶平衡温度计算结果 $\left({ }^{\circ} \mathrm{C}\right)$

\begin{tabular}{ccccc}
\hline 样品号 & $T(\mathrm{~W})$ & $T(\mathrm{WB})$ & $T(\mathrm{BK})$ & $T(\mathrm{~N})$ \\
\hline $08 \mathrm{TCH} 2-2$ & 1084 & 1065 & 1086 & 1091 \\
$08 \mathrm{TCH}-1$ & $/$ & $/$ & $/$ & 1084 \\
$08 \mathrm{TCH} 3-5$ & 1108 & 1101 & 1094 & 1126 \\
$08 \mathrm{TCH} 4-7$ & 1012 & 1022 & 1014 & 1024 \\
$08 \mathrm{TCH} 8-1$ & 998 & 1022 & 1017 & 1006 \\
$08 \mathrm{TCH}-3$ & $/$ & $/$ & $/$ & 1093 \\
$08 \mathrm{TCH} 2-4$ & 1073 & 1088 & 1076 & 1083 \\
$08 \mathrm{TCH} 4-5$ & 1022 & 1043 & 1057 & 1037 \\
\hline
\end{tabular}

山熔岩中的包体和斑晶可能具有相同的来源 ${ }^{[14]}$.

不含石榴石的包体平衡压力的计算目前仍是问 题. 近年来, McCarthy 等 ${ }^{[25]}$ 提出的压力计可以用来计 算含斜长石的包体的平衡压力, 该压力计曾被成功 用于计算安徽女山玄武岩中麻粒岩包体 ${ }^{[26]}$ 和汉诺坝 玄武岩中下地壳麻粒岩包体 ${ }^{[17]}$ 的平衡压力. 因此, 本 文尝试用该压力计计算了辉长岩包体的平衡压力, 结果如表 8 所示. 由表中可见, 平衡压力范围变化较 宽(0.49 0.99 GPa), 与温度没有明显对应关系.

\section{5 黑空山包体的来源和成因及岩浆演化特征}

\section{1 包体的来源}

辉长岩类包体具有“开放”的辉长或辉绿结构,
表 8 采用McCarthy 等 ${ }^{[25]}$ 压力计计算的包体平衡压力 ${ }^{a)}$

\begin{tabular}{clc}
\hline 包体编号 & $T\left({ }^{\circ} \mathrm{C}\right)$ & $P(\mathrm{GP})$ \\
\hline $08 \mathrm{TCH} 2-1-2$ & $1092^{*}$ & 0.94 \\
$08 \mathrm{TCH} 3-1-2$ & $1042^{*}$ & 0.49 \\
$08 \mathrm{TCH} 4-3-1$ & $1073^{*}$ & 0.89 \\
$08 \mathrm{TCH} 4-3-2$ & 1089 & 0.81 \\
$08 \mathrm{TCH} 8-1-3$ & 1125 & 0.54 \\
08TCH8-3-2 & 1089 & 0.85 \\
08TCH8-3-3 & 1000 & 0.99 \\
08TCH2-2b-2 & 1004 & 0.89 \\
08TCH2-4-1 & 1037 & 0.92 \\
08TCH4-5-1 & $1080^{*}$ & 0.72 \\
\hline
\end{tabular}

a) $* \mathrm{Nimis}^{[23]}$ 单斜辉石温度计计算的温度

明显不同于下地壳麻粒岩包体的粒状变晶结构 ${ }^{[17]}$. 辉石岩类包体中均未发现明显的变形现象, 其镶嵌 结构与堆积成因一致, 有别于幔源包体. 辉长岩类和 辉石岩类包体中的单斜辉石、斜方辉石成分均有别于 下地壳麻粒岩包体的上述矿物成分 ${ }^{[17]}$ (图 5). 辉石岩 包体中的橄榄石 $\operatorname{Fo}(77.3 \%$ 78.7\%) 远低于中国东部 和全球幔源包体橄榄石 $\mathrm{Fo}(86 \% \text { ～92\% })^{[2]}$ 其单斜辉石 和斜方辉石的 $\mathrm{Mg}^{\#}$ (分别为 $77.5 \%$ 84.0\%, 79.4\% $82.2 \%)$ 也都明显低于幔源包体的辉石 $\mathrm{Mg}^{\#}(89 \%$ $92 \%)$, 表明这些辉石岩类包体并非幔源包体. 另外, 辉长岩和辉石岩类包体的矿物成分与熔岩中斑晶矿 
物的成分基本一致, 辉长岩和辉石岩类包体的平衡 温度 $\left(1000 \sim 1125^{\circ} \mathrm{C}\right)$ 与斑晶的形成温度 $\left(998 \sim 1108^{\circ} \mathrm{C}\right)$ 基本一致, 并且包体中玻璃基质与熔岩玻璃基质的 成分也相近, 均指示了它们的同源性. 因此, 辉长岩 和辉石岩包体并非上地幔和下地壳包体, 而很可能 是在岩浆房内部形成的.

二辉橄榄岩包体 $(08 \mathrm{TCH} 2-2-1)$ 的残斑结构在幔 源包体中较为常见 ${ }^{[2,27]}$, 其橄榄石、单斜辉石和斜方 辉石均具有较高的 $\mathrm{Mg}^{\#}$, 符合幔源包体的成分特征, 可能为地幔橄榄岩来源. 腾冲地区莫霍界面平均深 度为 $40 \mathrm{~km}^{[28]}$, 莫霍面温度达 $1000^{\circ} \mathrm{C}$ 或以上 ${ }^{[29]}$, 但由 该包体计算所得的平衡温度 $\left(825^{\circ} \mathrm{C}\right)$ 明显低于该区正 常地幔的温度. 地幔包体在被上升岩浆捕获之前如 经历显著的冷却作用发生热重新平衡会具有较低的 平衡温度 ${ }^{[8]}$, 但由于目前在黑空山只发现 1 件二辉橄 榄岩包体样品, 形成较低平衡温度的真实原因仍需 更多样品进行研究.

\section{2 包体的成因及岩浆演化特征}

岩相学、矿物化学成分特征以及平衡温度计算结 果表明黑空山火山的镁铁质和超镁铁质包体与该火 山的高钾钙碱性熔岩具有密切的成因联系, 其形成 过程与岩浆在岩浆房中的停留、演化和喷发过程密切 相关.

原始的玄武质岩浆应来源于上地幔, 其上升时 并未直接喷出地表, 而是储存在地壳中的岩浆房内. 岩浆上升使其压力减小, 部分挥发份出溶. 在岩浆房 顶部岩浆与较冷的围岩接触, 热传导导致的热损耗 将使岩浆发生结晶作用. 由于岩浆房顶部也是气泡 集中带, 因此, 在此处形成晶体-气泡-液体带, 即具 “开放”结构的辉长岩顶衬 ${ }^{[6]}$. 此时, 岩浆房中发生辉 石的分离结晶作用, 形成的辉石晶体下沉到岩浆房 的底部, 构成辉石岩堆积体 ${ }^{[5]}$. 由黑空山第I期熔岩为 粗面玄武岩可推测岩浆在进入到岩浆房前可能已经 演化, 并且很有可能已经结晶出了大量的橄榄石, 所 以在熔岩斑晶和辉石岩堆积体中橄榄石较少见. 腾 冲黑空山各喷发期次中的包体成分并无差别(表 3), 但包体中的斜长石比熔岩斑晶更富钻(图 4), 说明辉 长岩类顶祄和辉石岩类堆积体在岩浆演化的早期就 开始形成, 并且可存在于几期喷发过程中. 当新的岩 浆补给时, 岩浆房内产生强烈的对流和均一化作用, 冲刷和破坏岩浆房顶部的辉长岩顶祄和底部的辉石
岩堆积体 ${ }^{[5,6]}$, 其碎片卷入岩浆中并被携带到地表, 成为熔岩中的包体(见图 7). 因此, 岩浆房的温压条 件可由包体的平衡温度 $\left(1000 \sim 1125^{\circ} \mathrm{C}\right)$ 和压力 $(0.49 \sim 0.99 \mathrm{GPa})$ 制约; 虽然 McCarthy压力计 ${ }^{[25]}$ 在低 压端 $(<0.6 \mathrm{GPa})$ 具有较大误差 ${ }^{[26]}$, 但总体计算结果表 明包体形成于中、下地壳深度(约 15 30 km), 该深度 与皇甫岗和姜朝松 ${ }^{[28]}$ 认为在 $20 \mathrm{~km}$ 左右深处残留一 个尺度较大的岩浆库一致.

随着岩浆房内部辉石的不断分离结晶, 岩浆逐 渐由基性向中酸性岩浆演化, 由第 II IV 期熔岩成分 可知, 晚期岩浆已经演化成为粗安质, 反映了黑空山 火山的岩浆演化过程与辉石的分离结晶作用密切相 关 ${ }^{[13]}$. 由熔岩基质的成分即使在在同一期中差异仍然 很大的特征推测岩浆房内部的岩浆由于分离结晶程度 不同可能形成了不同的成分分层, 可包括玄武安山 岩、玄武粗安岩、粗安岩、粗面岩和流纹岩. 当底部 岩浆补给时, 强烈的对流作用使各成分层岩浆产生混 合，导致喷发后产生的熔岩基质成分的复杂性.

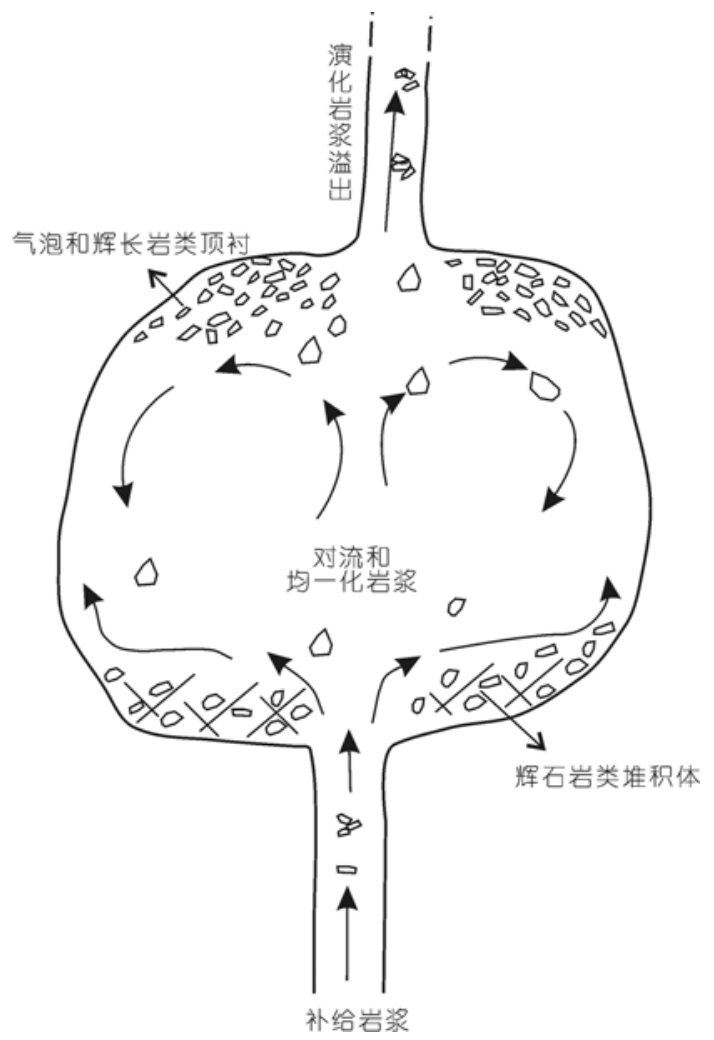

图 7 腾冲黑空山粗安岩中铁镁质-超铁镁质包体成因模型 示意图

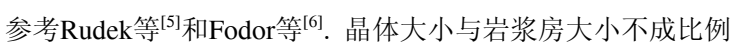




\section{6 结论}

(1) 腾冲黑空山粗安岩中的镁铁质和超镁铁质 包体包括辉长岩类 (包括辉长岩、辉长苏长岩、苏长 岩和橄榄苏长岩)、辉石岩类(包括二辉岩和单斜辉石 岩)以及极少量的二辉橄榄岩.

(2) 辉长岩类和辉石岩类包体与熔岩斑晶具有 同源性, 应来源于岩浆房内部, 其形成是岩浆结晶作 用和辉石分离结晶作用的结果. 二辉橄榄岩包体为
幔源包体，由补给岩浆将其带入岩浆房中.

(3) 辉长岩类和辉石岩类包体的平衡温度在 $1000 \sim 1125^{\circ} \mathrm{C}$ 之间，压力在 $0.49 \sim 0.99 \mathrm{GPa}$ 之间，反映 了岩浆房的温压条件.

(4) 岩浆房内部的岩浆由于分离结晶程度不同 有可能形成不同的成分分层，补给岩浆的侵入引起 的强烈对流作用使这些成分层发生混合作用，导致 熔岩基质成分的复杂性.

致谢衰心感谢中国科学院地质与地球物理研究所电子探针实验室的马玉光老师和中国地质大学(北京)电子探针 实验室的尹京武老师在电子探针分析过程中的热情支持和帮助; 感谢审稿人对本文的审阅和建设性的修改 意见.

\section{参考文献}

1 Nixon P H. Mantle Xenoliths. New York: John Wiley and Sons, 1987. 1-904

2 鄂莫岗，赵大升. 中国东部新生代玄武岩及深源岩石包体. 北京：地质出版社, 1987. 1-478

3 O'Reilly S Y, Griffin W L. 4-D lithospheric mapping: Methodology and examples. Tectonophys, 1996, 262: 3-18

4 Rudnick R L. Xenoliths - Samples of the lower continental crust. In: Fountain D, Arculus R, Kay R W, eds. Continental Lower Crust. Amsterdam: Elsevier, 1992. 269-316

5 Rudek E A, Fodor R V, Bauer G R. Petrology of ultramafic and mafic xenoliths in picrite of Kahoolawe Island, Hawaii. Bull Volcanol, 1992, 55: $74-84$

6 Fodor R V, Rudek E A, Bauer G R. Hawaiian magma- Reservoir processes as inferred from the petrology of gabbro xenoliths in basalt, Kahoolawe Island. Bull Volcanol, 1993, 55: 204-218

7 Fodor R V, Moore R B. Petrology of gabbroic xenoliths in 1960 Kilauea basalt: Crystalline remnants of prior (1955) magmatism. Bull Volcanol, 1994, 56: 62-74

8 Laiolo M, Cigolini C. Mafic and ultramafic xenoliths in San Bartolo lava field: New insights on the ascent and storage of Stromboli magmas. Bull Volcanol, 2006, 68: 653-670

9 刘若新. 中国的活火山. 北京：地震出版社, 2000.35

10 姜朝松，周瑞琦，周真恒，等. 滇西地区及邻区构造单元划分及其特征. 地震研究, 2000, 23: 21一 29

11 姜朝松. 腾冲新生代火山分布特征. 地震研究, 1998, 21: 309-319

12 李大明, 李奇, 陈文寄. 腾冲火山区上新世以来的火山活动. 岩石学报, 2000, 16: 362-370

13 樊祺诚, 刘若新, 魏海泉, 等. 腾冲活火山的岩浆演化. 地质论评, 1999, 45(增刊): 895-904

14 Cigolini C, Kudo A M. Xenoliths in recent basaltic andesite flows from Arenal Volcano, Costa Rica: Inference on the composition of the lower crust. Contr Mineral Petrol, 1987, 96: 381-390

15 史兰斌, 林传勇, 陈孝德, 等. 琼北第四纪玄武岩中微型地幔岩捕虏体的发现及其意义. 地震地质, 2003, 25(增刊): 33-42

16 Smith J V. Feldspar Minerals. New York: Springer-Verlag, 1974. 447

17 陈孝德, 林传勇, 史兰斌. 华北北部下地壳的流变学特征——河北汉诺坝下地壳包体提供的信息. 中国科学 D 辑: 地球科学, 2007, 37: $593-604$

18 Poldervaart A, Hess H H. Pyroxenes in the crystallization of basaltic magma. Journ Geol, 1951, 59: 472-489

19 Le Maitre R W, Bateman P, Dudek A, et al. A Classification of Igneous Rocks and Glossary of Terms. Oxford: Blackwell, 1989. 193

20 Wells P R A. Pyroxene thermometry in simple and complex systems. Contrib Mineral Petrol, 1977, 62: 129—139

21 Wood B J, Bano S. Garnet-orthopyroxene and orthopyroxene-clinopyroxene relationships in simple and complex systems. Contri Mineral Petrol, 1973, 42: 109-124

22 Brey G P, Kohler T. Geothermobarometry in four-phase lherzolites II. New thermobarometer and practical assessment of existing thermobarometers. J Petrol, 1990, 31: 1353-1378 
23 Nimis P, Taylor W R. Single clinopyroxene thermobarometry for garnet peridotites. Part I: Calibration and testing of a Cr-in-Cpx barometer and an enstatite-in-Cpx thermometer. Contrib Mineral Petrol, 2000, 139: 541-554

24 Huang X L, Xu Y G, Lo C H, et al. Exsolution lamellae in a clinopyroxene megacryst aggregate from cenozoic basalt, Leizhou Peninsula, South China: Petrography and chemical evolution. Contrib Mineral Petrol, 2007, 154: 691—705

25 McCarthy T C, Patino D A E. Empirical calibration of the silica-Ca-tschermak's-anorthite (SCAn) geobarometer. J Metamor Geol, 1998, 16: $675-686$

26 黄小龙, 徐义刚, 王汝成, 等. 安徽女山麻粒岩包体: 矿物学特征、下地壳地温曲线及其成因意义. 岩石学报, 2002, 18: 383一 391

27 林传勇, 黄小龙, 徐义刚, 等. 广东省雷州半岛上地幔热结构和流变学特征. 热带海洋学报, 2003, 22: 49-62

28 皇甫岗, 姜朝松. 腾冲火山研究. 昆明: 云南科技出版社, 2000. 418

29 阙荣举, 赵晋明. 腾冲火山地区的深部构造与地球物理场. 见: 刘若新, 编. 火山作用于人类环境. 北京: 地震出版社, 1995. 88 